\title{
Application of Systems Engineering to U.S. Department of Energy Privatization Project Selection at the Hanford Nuclear Reservation
}

\section{J. S. Layman}

June 6, 1999 - June 10, 1999

$9^{\text {th }}$ Annual International Symposium of the International Council on Systems Engineering (INCOSE ‘99)

This is a preprint of a paper intended for publication in a journal or proceedings. Since changes may be made before publication, this preprint should not be cited or reproduced without permission of the author.

This document was prepared as a account of work sponsored by an agency of the United States Government. Neither the United States Government nor any agency thereof, or any of their employees, makes any warranty, expressed or implied, or assumes any legal liability or responsibility for any third party's use, or the results of such use, of any information, apparatus, product or process disclosed in this report, or represents that its use by such third party would not infringe privately owned rights. The views expressed in this paper are not necessarily those of the U.S. Government or the sponsoring agency. 


\title{
Application of Systems Engineering to U.S. Department of Energy Privatization Project Selection at the Hanford Nuclear Reservation
}

\author{
John S. Layman \\ Lockheed Martin Idaho Technologies Company \\ Idaho National Engineering \& Environmental Laboratory \\ 2525 Fremont Ave. \\ P.O. Box 1625 Mail Stop 3750 \\ Idaho Falls, ID 83415-3805 \\ LAYMJS@inel.gov
}

\begin{abstract}
The privatization efforts at the U.S. Department of Energy's Hanford Nuclear Reservation have been very successful primarily due to a disciplined process for project selection and execution.
\end{abstract}

Early in the development of Privatization at Hanford, the Department of Energy determined that a disciplined alternatives generation and analysis (AGA) process would furnish the candidate projects with the best probability for success. Many factors had to be considered in the selection of projects. Westinghouse Hanford Company was assigned to develop this process and facilitate the selection of the first round of candidate privatization projects.

Team members for the AGA process were assembled from all concerned organizations and skill groups. Among the selection criteria were legal, financial and technical considerations which had to be weighed.

\section{INTRODUCTION}

Although this paper is very basic to the practice of Systems Engineering, the author provides insight into how Systems Engineering principals have been applied to a developing field, privatization of government activities. The use of pair-wise comparison on selection criteria uses text-book methods in a real world application. This paper demonstrates how Systems Engineering tools can and should be applied to all complex new endeavors.

\section{BACKGROUND}

In the late 1980s, the United States Department of Energy (DOE) began to recognize the potential benefits of a new kind of contracting, privatization. This contracting would take existing and new work scopes and request private companies to propose new, more cost effective ways of completing that work. The work scope could be very simple or complex.
Common to all privatization is allowing the private vendor to operate under a different set of rules which allows more cost effective operation. The profit motive of the private sector drives the cost of providing services down and provides a less expensive product to the government.

When this task started, processes for the selection and comparison of candidate projects had not been defined. In addition, the limitations and requirements for privatization were not understood. At the DOE's Hanford Nuclear Reservation, the DOE and its management and operating contractor, Westinghouse Hanford Company (WHC) utilized a structured approach to determine candidate selection criteria and to select candidates.

\section{INITIAL CANDIDATE IDENTIFICATION}

After the pilot projects were well underway, WHC requested that each of its divisions volunteer a list of candidates of work scope that had the potential for privatization. Guidelines were provided concerning what made a good candidate. The candidates suggested were to be put into a formal alternatives analysis from which privatization projects would be selected.

Unfortunately, the incentive to volunteer work scope within a manager's purview was absent. As a result, very few candidates were suggested. Those that were suggested were often from another manager's division. It was decided that a more independent method for candidate project selection was necessary.

Selected experts from WHC and DOE reviewed a list of all Hanford Site programs and projects to jdentify over 700 candidate activities to be considered. One

\footnotetext{
${ }^{1}$ The selection process is referenced from a predicisional draft document titled Red Team
} 
of the key identification criteria was a substantial budget (greater than $\$ 1$ million). Because the process of contracting for major service contracts is very expensive, the potential for savings had to be present for a candidate to be viable.

The list of candidates went through a macro screening process that eliminated projects that were core to the operations of the Hanford Site or were not available for privatization due to other contracting activities. All identified stakeholders participated in the review of candidates.

\section{SELECTION AND WEIGHTING OF CRITERIA}

The team for criteria selection was chosen from identified stakeholders. A brainstorming of potential criteria was conducted and both "musts" (required criteria) and "wants" (desired criteria) were identified. The criteria are provided and described in Attachment A.

Weighting of "wants" criteria was performed using a pair-wise comparison. The team compared one criteria against all others. A total score for each criteria was developed.

As a result of the weighting process, criterion 12, Better Application of Proven Technology, was eliminated. This criterion was weighted below all others and found to be insignificant in the selection process. In addition, criteria 6,10 , and 11 were found to be related. A combination of these three criteria was elected because the individual criteria had fairly small weights. This decision helped to reduce the total scoreing process. The results of the weighting process is shown in Figure 1.

\section{CRITERIA WEIGHTING PROCESS}

\begin{tabular}{|c|c|c|c|c|c|c|c|c|c|c|c|c|}
\hline 1 & 2 & 3 & 4 & 5 & 6 & 7 & 8 & 9 & 10 & 11 & 12 & 13 \\
\hline 1 & $\begin{array}{c}\text { B1 } \\
=3\end{array}$ & $\begin{array}{r}\mathrm{B3} \\
=2\end{array}$ & $\begin{array}{l}\text { B4 } \\
=2\end{array}$ & 0 & $\begin{array}{l}\text { B1 } \\
\text { =3 }\end{array}$ & $\begin{array}{l}\mathrm{B} 1 \\
=1\end{array}$ & $\begin{array}{l}\text { B1 } \\
=1\end{array}$ & $\begin{array}{l}\text { B1 } \\
=1\end{array}$ & $\begin{array}{c}B 1= \\
1\end{array}$ & $\begin{array}{c}\mathrm{B} 1= \\
\mathbf{3}\end{array}$ & & $\begin{array}{c}\mathrm{B} 1= \\
2\end{array}$ \\
\hline 2 & & $\begin{array}{r}\text { B3 } \\
=1\end{array}$ & $\begin{array}{l}\text { B2 } \\
=1\end{array}$ & $\begin{array}{l}\text { B5 } \\
=1\end{array}$ & $\begin{array}{l}\text { B2 } \\
=2\end{array}$ & $\begin{array}{c}\text { B2 } \\
=3\end{array}$ & $\begin{array}{l}\text { B2 } \\
=1\end{array}$ & 0 & 0 & $\begin{array}{c}\mathrm{B} 2= \\
2\end{array}$ & & 0 \\
\hline & 3 & & $\begin{array}{r}\text { B3 } \\
=2\end{array}$ & 0 & $\begin{array}{c}\text { B3 } \\
=3\end{array}$ & $\begin{array}{c}\mathbf{B 3} \\
=\mathbf{3}\end{array}$ & $\begin{array}{r}\text { B3 } \\
=3\end{array}$ & 0 & $\begin{array}{c}\text { B3 } \\
2\end{array}$ & 0 & & 0 \\
\hline & & 4 & & 0 & $\begin{array}{l}\text { B4 } \\
=1\end{array}$ & $\begin{array}{c}\text { B4 } \\
=2\end{array}$ & $\begin{array}{l}\text { B4 } \\
=2\end{array}$ & 0 & $\begin{array}{c}\text { B4 }= \\
1\end{array}$ & $\begin{array}{c}\text { B44 }= \\
1\end{array}$ & & 0 \\
\hline
\end{tabular}

Phase I Analysis of Current and Planned Hanford Site Functions for Possible Privatization, U.S. Department of Energy, Richland Field Office, October 15, 1992.

\footnotetext{
${ }^{2}$ The decision analysis process used followed the guidelines provided in The New Rational Manager by Charles H. Kepner and Benjamin B. Tregoe, 1981.
}

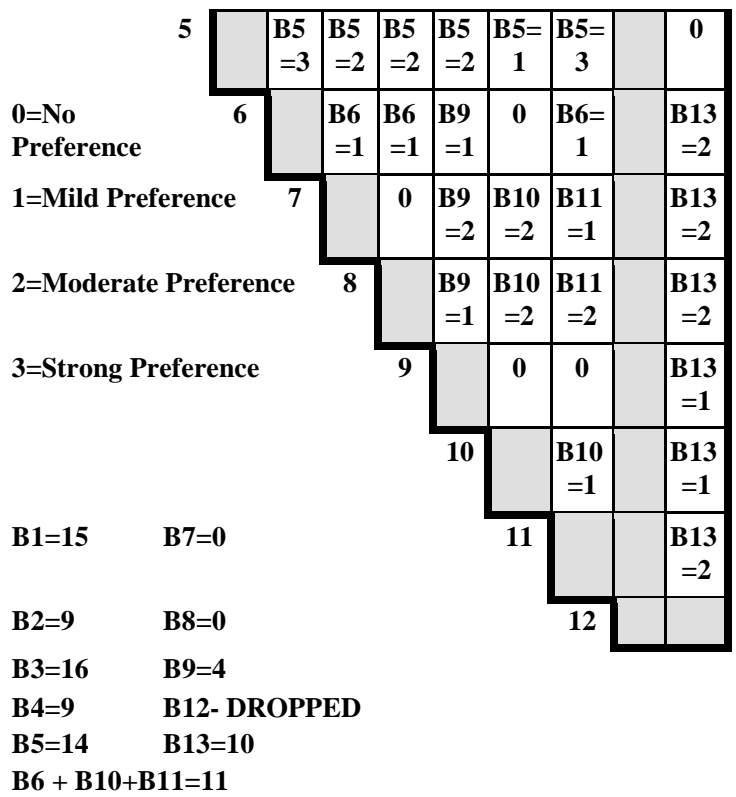

Figure 1, Criteria Weighting Process Results

\section{SELECTION OF FIRST ROUND CANDIDATE PROJECTS}

After the macro screening process, a list of 150 activities to be considered remained. Using this list, a formal AGA study was conducted and documented. This process served to further reduce the number of candidates and then rate remaining candidates.

The 150 potential candidates were judged against a set of "must" criteria. These criteria evaluated candidates in areas that were essential for privatization to succeed. These criteria were:

- Well Defined Work Scope,

- Industry Capability, and

- Significant Potential Cost Savings.

Eighty potential candidates passed the "must" criteria and were judged against a set of "wants" criteria.

One particularly useful technique was recording the scores real-time on a computer spread-sheet and displaying those results by projection onto a screen. Once all scores were entered, the process of finding the highest rated alternatives was as simple as sorting the spreadsheet.

One error in the scoring process was to allow the candidate project selection team to view the results of the weighted score for each candidate project as the alternative was being scored. This allowed team members to adjust particular scores to help alternatives they felt were more suitable. It is recommended that the weights of criteria not be applied until after all alternatives are scored. This recommendation will allow the preferred alternatives to rise to the top without adjustments to scores 
resulting from pre-selection of "pet" candidate projects.

The result was a list of 80 candidates with a relative score for each. The bottom 43 candidates were not considered worth additional effort because of relatively low total weighted score. The top 37 candidates were forwarded to the Department of Energy management for approval to proceed. The selection process is illustrated in Figure 2.

\section{CONCLUSIONS}

The use of a structured AGA approach to alternatives selection provides justification for the selection of particular alternatives. As a result of using a disciplined approach, the selected alternatives (candidate projects) were very well suited for privatization and a high success ratio was achieved.

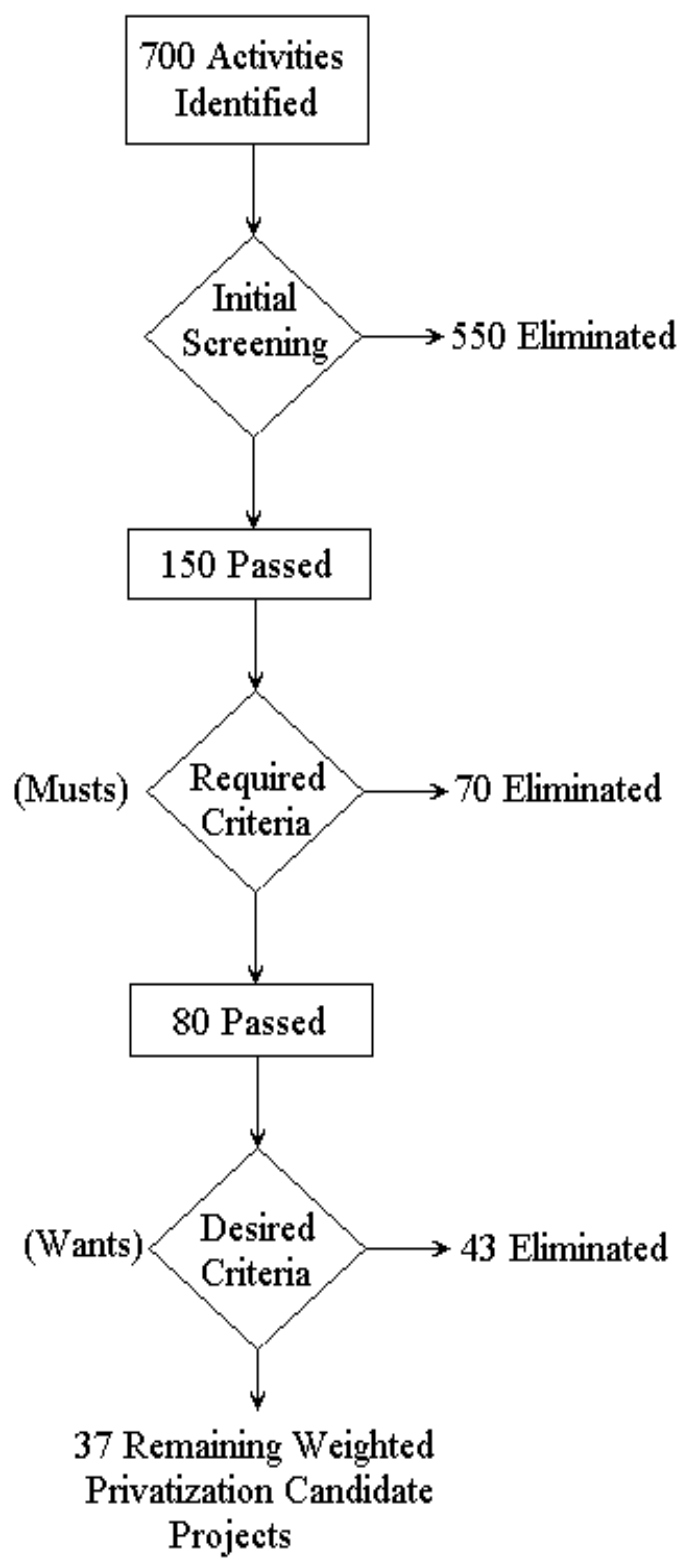

Figure 2, Alternatives Selection Process 


\section{Attachment A, Evaluation Criteria and Scoring}

The "A" criteria were "musts" / requirements. They allowed us to eliminate many suggested projects with a very quick review process. These criteria did not rate the commercial alternative but serve as go/no go gates.

Because over 150 projects were on the list to be considered, this process was important to completing a review in a timely way. Some call this process a "Killer Trade Study". The required criteria were:

1. Well-Defined Workscope - Unless the workscope can be clearly defined, it will be impossible for private industry to provide a reasonable bid for the required product or service and, therefore, unlikely that an overall benefit to the government can be obtained. In addition, the workscope must be sufficiently separable from other Hanford activity to allow private sector operation without unacceptable interface problems. If the workscope cannot be defined so that the activity is amenable to unit (fixed) price contracting then it is probably not suitable for consideration as a commercial alternative.

2. Industry Capability and Interest - Evidence must exist that private industry has the current capability and experience to provide the needed product or service, timely and with required quality/reliability. DOE must also be able to offer a contract that will provide sufficient benefit to the private sector to justify the risks of private sector investment of capital and other resources as compared to other private sector investment opportunities. Such things as projected volumes, acceptable unit costs, contract length, etc., must provide the potential benefit.

3. Capital/Cost Savings - Initial evaluation using available information should indicate that the commercial alternative approach will result in a capital cost savings and a life cycle cost savings to the government, as compared to the current or normal government approach (e.g., capital funding for new or upgraded facilities or equipment coupled with operating costs). Cost savings can accrue from reduced private industry construction costs, reduced layers of procedures and government requirements, multiple customers, different technologies, improved schedules or other aspects. An activity that can be performed off of Government property has opportunities to comply with private, national standards rather than the many layers of DOE requirements.

The "B" criteria were wants / desires. The evaluation of "B" criteria was called Criteria Analysis. Once the go/no go gates were passed (Required Criteria), the Criteria Analysis was used to measure the relative merit of the alternative relative to other alternatives. Some "B" criteria were repeats of the "A" criteria. For example, not only was it important that there be a cost savings, but, the size of the cost savings was important to the selection. The "B" criteria were:

1. Well-Defined Workscope - Can the work scope be clearly defined and separable from other activities so that it offers a clear, defined quantity for private industry to develop a cost effective proposal. Examples of activities with well defined work scopes include laundry services and waste processes such as treatment of a specific waste stream or packaging of solid wastes, a specific engineering task, etc.

2. Industry Capability/Interest - Does industry have a demonstrated capability and experience? Is there any specific aspect that would put either the government or private industry in a better position to provide the product or service? Can the procurement be packaged to be sufficiently attractive to private industry to invest its resources and accept the resulting business risks? Factors that provide sufficient incentive to the private sector generally include long-term contracts, high projected volumes, reasonable unit costs.

3. DOE Capital Funding Eliminated - Will new capital and/or expense funding be required to maintain the current operation for the long term? Can this funding be saved by using the commercial alternative? The commercial alternatives will require private industry investments and limit government expenditures to payment of unit costs for products and services over long-term contracts.

4. Reduced Life Cycle Cost - Will the commercial alternative approach provide a significant reduction in the life cycle cost of the subject activity? How significant are the expected cost savings? Lower cost will almost always be the major factor that is needed to justify the commercial alternative approach over normal government financing. Factors which lead to lower life cycle costs include ability to serve multiple customers, lower building costs, lower overhead costs, more rapid construction, salaries, benefits, etc. 
5. Workforce Impact - Will shifting the function to the private sector result in potential impacts to the existing workforce?

6. Improved Operation or Schedules - Does the commercial alternative approach offer the opportunity to significantly improve operations or the ability to maintain required schedules as compared to the governments' processes.

For a large facility, the funding, design, construction, and startup periods to build a new capability on a government site takes many years._Private Industry can use existing facilities to provide products and services or rapidly build new facilities without waiting for the congressional budget and funding cycles.

7. Multiple Customers - Will the private industry supplier of the product or service be able to serve multiple customers and thus reduce government costs (spread overhead costs over a wider base) or provide better service?

8. Multiple Suppliers - Is there more than one potential provider in the private sector for the product or service. Single source procurements are generally less desirable than where there is competition among two or more potential suppliers and will probably result in higher prices because of the lack of competition. In addition, a single source means there are no back-up suppliers should the selected entity not be able to provide the product or service.

9. Contract Term/Authority - What are the long term needs of DOE for the product or service? Can the commercial alternative be implemented under current authority and current or projected budgets? Will private industry require any guarantees, such as minimum levels of funding or coverage of amortization costs if the government decides it no longer needs the products or services? If special funding guarantees are required this represents a negative benefit to DOE because budget coverage of the guarantees will probably be required up front in DOE's budget.

Is the contract term long enough to interest the private sector? The Atomic Energy Act of 1954, amended, section 161(u)(2), allows DOE to enter into long-term contracts with the private sector. Although the language of section 161(u)(2) is somewhat ambiguous, DOE Senior Counsel has interpreted this section to provide for a contract term of 10 years, with options for renewal.

10. Operational Interfaces - Are the interface requirements clearly defined? The commercial alternative should be able to function separately and should not represent a key step in a multistep process.

11. Better Use of Government Resources - Will the commercial alternative approach allow significantly better use of government resources? Could WHC staff or management be more effectively utilized on other work? Will the commercial alternative enhance or compliment current operation? This will not normally be a major factor, however, it could be significant if WHC needs to free up key resources to focus on particular problem areas.

12. Better Application of Proven Technology - Will the commercial alternative allow introduction of new or advanced technology which will significantly improve operations, safety or environmental protection? In some cases private industry may already have a technology that DOE would have to develop or buy the rights to use.

13. Specific Benefit/Risk - Will the commercial alternative provide a specific benefit or risk other than those already identified under the above criteria that should be especially considered in evaluating the its potential? Risk examples could include schedule contraints imposed by the NEPA process, legal liability from transportation of mixed waste offsite, etc. Examples of benefits might include local community goodwill, accelerating Tri Party Agreement milestones, etc.

On the following page is a form used to document the results on each of the 37 forwarded candidate projects (alternatives). Before the end of the process, this form was edited to reflect the elimination and combination of criteria and the weight factors.

In the scoring process, a rating from 1 to 5 is assigned to each of the Evaluation Criteria for each alternative (candidate project) with a " 5 " representing the highest rating in favor of the privatization alternative. The ratings 
for Criterion B3, "DOE Capital Funding Eliminated," and Criterion B4, "Reduced Life Cycle Cost," was assigned based on the following scale of savings:

$$
\begin{array}{ll}
0 & \text { No savings } \\
1 & \$ 0 \text { to } \$ 2 \text { million } \\
2 & \$ 2 \text { to } \$ 10 \text { million } \\
3 & \$ 10 \text { to } \$ 25 \text { million } \\
4 & \$ 25 \text { to } \$ 100 \text { million } \\
5 & >\$ 100 \text { million }
\end{array}
$$

Each "wants" criteria had a similar scale, although some were less measurable. The rating for a specific criterion is multiplied by the weighting factor assigned to that criterion. The total points for each criterion are added to yield a totaled weighted score. The score was used as an indicator of the potential for privatization of a project relative to other projects evaluated. 


\section{ALTERNATIVE CRITERIA EVALUATION (Rev. 0)}

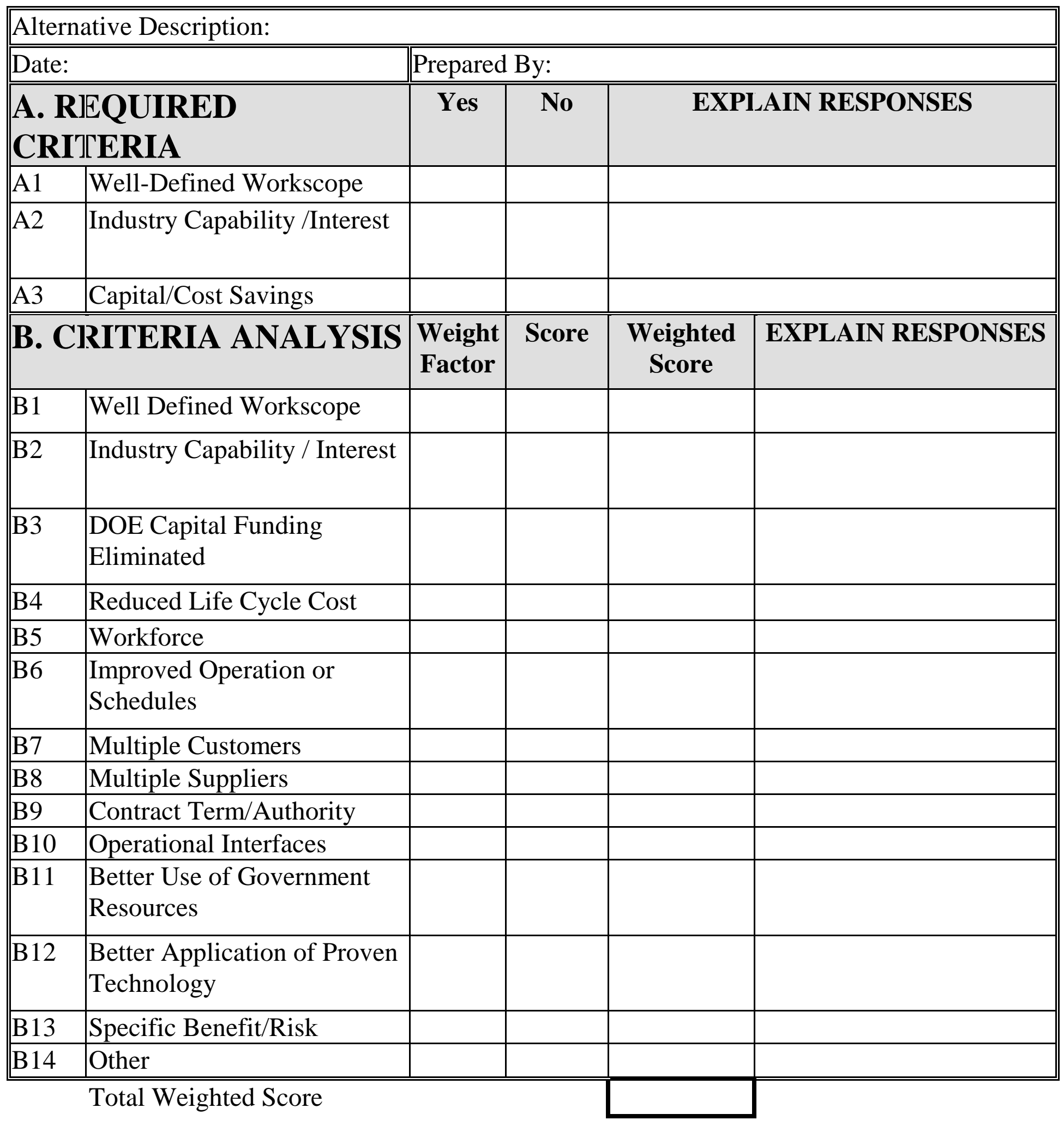

